\title{
Spirituality, Religion, and Aging Illuminations for Therapeutic Practice
}

Holly Nelson-Becker

Loyola University Chicago, hnelsonbecker@luc.edu

Follow this and additional works at: https://ecommons.luc.edu/facultybooks

Part of the Social Work Commons

\section{Recommended Citation}

Nelson-Becker, Holly, "Spirituality, Religion, and Aging Illuminations for Therapeutic Practice" (2017). Faculty Books. 125.

https://ecommons.luc.edu/facultybooks/125

This Book is brought to you for free and open access by Loyola eCommons. It has been accepted for inclusion in Faculty Books by an authorized administrator of Loyola eCommons. For more information, please contact ecommons@luc.edu.

\section{(c) $(\ominus \ominus$}

This work is licensed under a Creative Commons Attribution-Noncommercial-No Derivative Works 3.0 License. 


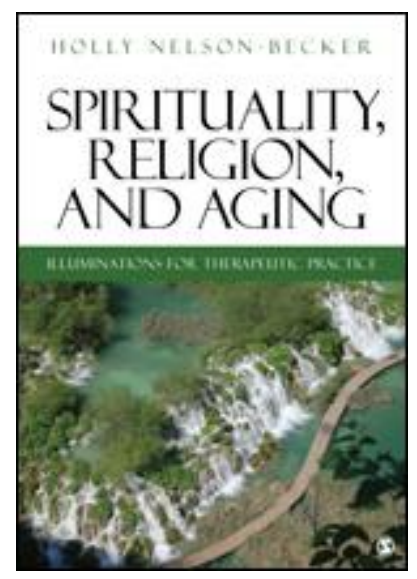

\section{Spirituality, Religion, and Aging}

Illuminations for Therapeutic Practice

Holly Nelson-Becker - Loyola University of Chicago, USA

February 2017 | 488 pages | SAGE Publications, Inc

\begin{tabular}{llll} 
Format & Published Date & ISBN & Price \\
\hline Paperback & $02 / 15 / 2017$ & 9781412981361 & $\$ 40.00$ \\
Electronic Version & $02 / 21 / 2017$ & 9781483315249 & $\$ 32.00$
\end{tabular}

This highly integrative book was written for students, professionals in aging, ministers, and older adults themselves. Readers will gain the knowledge and skills they need to assess, engage, and address the spiritual and religious needs of older persons. Taking a fresh approach that breaks new ground in the field, the author discusses eight major world religions and covers values and ethics, theories, interventions, health and caregiving, depression and anxiety, dementia, and the end of life. Meditations and exercises throughout the book allow readers to expand and explore their personal understanding of spirituality. Referencing the latest research, the book includes assessments and skill-based tools designed to help practitioners enhance the mental health of older people.

\section{KEY FEATURES:}

- An integrated, interdisciplinary approach prepares future mental health professionals to work on teams and bring the best of their disciplinary knowledge to contexts of transdisciplinary practice.

- A standard chapter format helps readers develop a deeper understanding of spirituality and religion in aging and includes questions for discussion; a suggested meditation; exercises; related websites; and recommended readings.

- Important core information on aging includes necessary foundational gerontological content and the latest concepts and published research in spirituality and religion within aging communities.

- Seven fully developed case studies help students consider important issues in working with clients' spiritual and religious beliefs, values, and practices.

- Detailed examples of clinical strategies prepare mental health professionals to support personal strengths and help clients cope with spiritual struggles. 
Table Of Contents:

Foreword

Preface

About the Author

Invitation

PART I • PRINCIPLES OF SPIRITUALITY AND RELIGION FOR GERONTOLOGICAL PRACTICE

Chapter 1 • The Importance of Spirituality and Religion for Gerontology

Aging in a Postmodern Time

Practical and Orienting Definitions

Portrait of Religion and Aging in the United States

The Demographics of Old Age

Intersectionalities Among Spirituality, Gender Identity, and Older Age

A Brief History of Spirituality Across Disciplines

Assumptions About Religion and Spirituality

The Legacy of Aging in Modern Times 
New Directions

Clinical Aspects of Later-Life Spiritual Journeys

Summary

Questions for Discussion

Introduction to Meditation Exercises

Meditation: Breath

Exploring Your Spirituality: Introduction

Exploring Your Spirituality: Basic Questions

Exploring Your Spirituality: Connect With Nature

Websites

Chapter 2 - Defining Religion and Spirituality: Professional and Practical Philosophies

Shifting Foundations

Religion and Spirituality: What Do They Mean?

Who or What Is God?

Professional Definitions of Religion

Background of Spirituality and Its Relevance for Aging

Other Aspects: Existential Well-Being, Spiritual Well-Being, Spiritual Suffering, and Spiritual Care

Spirituality, Standards of Care, and the Professions

Summary 
Case Study: Spiritual Suffering and Spiritual Crisis

Questions for Discussion

Meditation: Relaxation, Also Known as Body Scan

Assignment: Interview an Older Adult

Exploring Your Spirituality: Objects of Meaning and Memory

Websites

Recommended Reading

Chapter $3 \cdot$ Values and Ethics With Older Adults

Empathy, Compassion, or Sympathy

Virtue Ethics

Religion and Ethics

Spiritual and Existentialist/Humanist Ethics

Nonviolence and Interreligious Harmony

Ethical Theory for Practice in Brief

Value Dimensions for Practice

Boundaries in Ethical Practice

End-of-Life Ethics

End-of-Life Case

Intergenerational Ethics 
The Rights of Older Adults

Madrid International Plan of Action on Aging, 2002 and Beyond

Generosity, Spiritual Wealth, and Service

Summary

Questions for Discussion

Meditation: Changing of the Seasons

Exploring Your Spirituality: Spiritual-Ethical Will

Exploring Your Spirituality: Vision

Exploring Your Spirituality: Scent

Websites

Recommended Reading

Chapter 4 • Religion and Spirituality in Theory

Why Does Theory Matter?

Social Gerontology Perspectives and Theories

Theories of Individual Behavior

Developmental and Transpersonal Theorists

Humanism

Transpersonal Psychology

Theories of Positive Aging, Successful Aging, and Strengths 
Theory Integration

Summary

Case Study: Letha Bainbridge

Questions for Discussion

Meditation: The Tree That Was Planted the Day You Were Born

Exploring Your Spirituality: Developing a Spiritual History

Exploring Your Spirituality: Defining a Peak Experience

Websites

Recommended Reading

Chapter $5 \cdot$ Religion and Older Adults

Judaism

Christianity

American Indian Religion/Spirituality

Islam

Hinduism

Buddhism

Confucianism

Daoism

Integration of Religious Philosophies and Aging 
Summary

Questions for Discussion

Assignment: Framing the Landscape of Religious Ritual

Assignment: Sacred Spaces Exercise

Meditation: Present Moment Awareness

Exploring Your Spirituality: Rhythm and Movement

Exploring Your Spirituality: Pilgrimage

Websites

Recommended Reading

PART II • PRACTICE DIMENSIONS OF SPIRITUALITY AND RELIGION IN AGING

Chapter 6 • Spirituality and Religion in Clinical Assessment

What's Important About Religion and Assessment?

Mental Health Assessment

The Clinical Assessment Process With Spirituality

Clinical Assessment Protocols

Rapid Assessment Instrument Protocols

Spiritual Distress Assessment

Summary 
Questions for Discussion

Meditation: Focused Attention

Exploring Your Spirituality: Discernment

Exploring Your Spirituality: Emotional Mindfulness

Exploring Your Spirituality: Composition of the Place

Website

Recommended Reading

Chapter 7 - Religious and Spiritual Interventions With Clients

Section 1: Philosophical Approaches to Therapy With Older People

Section 2: Mid-Range Interventions of Care

Section 3: Micro-Level Individual Spiritual Care Activities

Summary

Questions for Discussion

Meditation: Bringing Yourself Together

Exploring Your Spirituality: The Labyrinth

Exploring Your Spirituality: Building Intentional Spiritual Places

Websites

Recommended Reading 
Chapter 8 • Spirituality, Religion, and Health

Definitions of Health

Aging and the Body: Failing Health

Historical Views on Religion and Health

From Holistic Historical Renderings to Modern Cultural Health Considerations

Suffering

Views of Health From Religious Perspectives

Research on the Intersections Between Religion and Health

\section{Caregiving}

Prayers, Rituals, and Symbols

Hope, Meaning/Purpose, and Mental Health

Summary

Case Study: Health and Spirituality

Questions for Discussion

Meditation: Taste

Exploring Your Spirituality: Touch

Exploring Your Spirituality: Taste and Savoring

Websites

Recommended Reading 
Chapter 9 • Spirituality in Emotion, Depression, and Anxiety

Emotions and Their Meaning

Emotion and the Sacred

Indicators and Etiology of Depression

Depression Types

Depression as Cultural Marker

Epidemiology

Eudaimonia

Other Depression-Like States: Demoralization, Desolation and the Dark Night of the Soul, and Despair

Research Related to Depression and Religion

Interventions

Spiritual Interventions and Depression/Desolation

Anxiety

Anxiety Interventions

Summary

Case Study: Depression and Spirituality

Questions for Discussion

Meditation: Self-Compassion With Movement

Exploring Your Spirituality: Regret 
Exploring Your Spirituality: Fighting Fear

Exploring Your Spirituality: Gratitude

Websites

Recommended Reading

Chapter 10 - Memory, Dementia, and Spiritual Care

Memory and Growing Older

Types of Dementia and Behavioral Indicators

Delirium, Depression, Thyroid, Vitamin Deficiencies, Alcoholism, and Other Temporary Causes of Dementia

Prevalence of Dementia

Disclosure of $A D$ and Related Dementia: A Counseling Concern

Another Perspective on Dementia

Spirituality and the Self

Understanding Need-Driven, Dementia-Compromised Behavior

Literature Related to Spiritual Aspects of Dementia and Dementia Care Practice

Religious and Spiritual Practice Principles for the Person With Dementia

Arts-Based Interventions

Summary

Questions for Discussion 
Meditation: Walking

Exploring Your Spirituality: Sound

Exploring Your Spirituality: Tonglen Practice to Increase Compassion

Websites

Recommended Reading: Information for Professionals

Recommended Reading: Memoirs on Dementia

Chapter $11 \cdot$ Spirituality at the End of Life

The Nature of Dying

Spirituality at the End of Life: Historical Context

Older Adults in Hospice Care

Modern Palliative and Hospice Care

National Consensus Project Guidelines

A Spiritual Care Model

Spiritual Care at the End of Life: Spiritual Practices

Communication at the End of Life

Summary

Questions for Discussion

Assignment: Spirituality, Religion, and Loss

Meditation: Refreshing the Senses 
Exploring Your Spirituality: Creating Your Own Obituary- An Opportunity for Reflection

Exploring Your Spirituality: Plan Your Memorial or Funeral Service

Exploring Your Spirituality: A Meeting With Death

Websites

Recommended Reading

Chapter $12 \cdot$ Integration

Integration of Religion and Spirituality With Professional Practice

Functions of Religion

Trends in Spirituality

A Practical Philosophy or Practical Theology

Spiritual Orientation Dissimilarity Between Client and Practitioner

Working With Spiritual Unease and Distress in Disasters

Evaluation

Interprofessional Practice and Spirituality

Self-Care and Mindfulness: Spiritual Awareness

Contemplative Practices for Renewal

Self-Compassion

A Personal Note on the Challenge of Spiritual Integration

Summary 
Questions for Discussion

Meditation: Color

Exploring Your Spirituality: Balance and Equipoise

Exploring Your Spirituality: Self-Integration

Websites

Recommended Reading

Chapter 13 - Lessons for Building Spiritual Resilience and Epilogue

Section 1: Lessons For Building Resilience

Section 2: Epilogue

Benediction

Parting Thoughts

Questions for Discussion

Assignment: Visioning

Meditation: A Meditation With Music-The Great Bell Chant

Meditation: A Meditation With Movement-Five Ages Dancing

Meditation: A Meditation Using Hands or Fingers

Meditation: MBSR Mindfulness Eight-Week Course

Exploring Your Spirituality: Working With Light

Exploring Your Spirituality: Participation and Reciprocity 
Website

Recommended Reading

Appendix: Older Adult Definitions

References

Index

\section{Reviews:}

"Professor Holly Nelson-Becker's groundbreaking book provides a holistic framework of knowledge, values, and clinical practices that promote gerontological practitioners' comfort and competence to address spirituality and religion. Her subtitle key word 'illuminations' is apropos. Nelson-Becker deftly integrates understandings from social work, nursing, psychology, counseling, health sciences, chaplaincy, and other fields to craft an interdisciplinary approach that is sensitive to the vulnerabilities and strengths of aging and dying that reveal, as she said, "openings for light." She synergizes profound insights with practical daily life realities. She presents these insights with scientific acumen and poetic sensibility. All of this is supported by her extensive experience as a clinician, researcher, educator, and pastoral minister. The resulting approach to gerontological practice respects diverse religious and nonreligious expressions of clients' spiritual journeys and supports the professional and spiritual growth of clinicians. I enthusiastically recommend this book."

Edward R. Canda, Director of the Spiritual Diversity Initiative

The University of Kansas School of Social Welfare

"Religion and spirituality play an important role in the lives of older adults. This book will be an important resource to aid helping professionals to become more aware of this fact and integrate this awareness in their work. The book will also be helpful to clergy and chaplains who frequently provide care to older adults and their loved one but rarely have any training in gerontology. The book includes helpful discussions of important topics including spiritual assessment, care for those with dementia and care at the end of life."

George Fitchett

Rush University Medical Center

"Spirituality is a vital part of aging and this book is a comprehensive resource providing both theoretical 
and clinical insight to understand the complex aspects of spirituality for older people. The text is an outstanding guide for all disciplines."

Betty Ferrell

City of Hope Medical Center

"In this essential and insightful book for our times, Holly Nelson-Becker draws upon current research and scholarship regarding spirituality, religion, and aging from a range of disciplines and shares stories, examples, and anecdotes from her own work with older adults and their families. Readers will appreciate this approach of bringing together findings from scientific research and insights from practice and presenting them in an easy to understand language and style. One of the key strengths of this book is its accessibility and applicability for practitioners. Although high-quality research is being conducted and published, oftentimes this work is not reaching health practitioners, social workers, and therapists who are serving older adults and their caregivers. This book has the potential to connect research and practice audiences around these important topics.

Given the continuing increase in the population of older adults from varied ethnic and cultural backgrounds and the spiritual and religious challenges they experience, the book includes a continuing discussion of diverse faith traditions and their implications for mental health practitioners. Another important strength of the book is its emphasis on active learning. Each chapter includes discussion questions, meditation exercises, spiritual exercises, and case studies aimed at engaging readers in using what they are learning. Internet and other resources are also included to help interested readers in obtaining additional information on topics of their interest. These pedagogical features further contribute to the books' overall goal of preparing students and health care providers to address psychological and spiritual needs of older people from varied ethnic and cultural backgrounds. This text is a timely and relevant contribution to the growing body of work on spirituality, religion, and aging that has the potential to further knowledge, have meaningful impact for multiple audiences, and ultimately improve the lives of older adults."

Chandra M. Mehrotra, PhD

The College of St. Scholastica 